Revue d'histoire de l'Amérique française

REYUE D.HISTOIRE DE L'AMÉRIQUE FRANÇAISE

\title{
BOUCHARD, Gérard et Martine SEGALEN, dir., Une langue, deux cultures. Rites et symboles en France et au Québec (Québec, Les Presses de l’Université Laval, 1997), 350 p.
}

\section{Denise Lemieux}

Volume 52, numéro 2, automne 1998

URI : https://id.erudit.org/iderudit/005526ar

DOI : https://doi.org/10.7202/005526ar

Aller au sommaire du numéro

Éditeur(s)

Institut d'histoire de l'Amérique française

ISSN

0035-2357 (imprimé)

1492-1383 (numérique)

Découvrir la revue

Citer ce compte rendu

Lemieux, D. (1998). Compte rendu de [BOUCHARD, Gérard et Martine SEGALEN, dir., Une langue, deux cultures. Rites et symboles en France et au Québec (Québec, Les Presses de l'Université Laval, 1997), 350 p.] Revue d'histoire de l'Amérique française, 52(2), 255-258.

https://doi.org/10.7202/005526ar d'utilisation que vous pouvez consulter en ligne. 


\section{COMPTES RENDUS}

BOUCHARD, Gérard et Martine SEGALEN, dir., Une langue, deux cultures. Rites et symboles en France et au Québec (Québec, Les Presses de l'Université Laval, 1997), 350 p.

À l'instar de l'ouvrage précédent publié à l'IREP, le livre dirigé par Gérard Bouchard et Martine Segalen intitulé Une langue, deux cultures. Rites et symboles en France et au Québec, rassemble principalement les travaux de l'équipe internationale qui, depuis 1991, poursuit des recherches comparées sur les rituels en divers lieux appartenant ou ayant appartenu à une histoire commune. Il s'agit dans le cas présent de la France, du Québec et de l'Algérie. Cette recherche s'inscrit dans la problématique des continuités et discontinuités culturelles en contexte de migration, une question d'actualité. En choisissant comme objet le rituel sous ses formes de rites de passage et de rites thérapeutiques, les chercheurs se donnaient sans doute à première vue un objet susceptible de révéler des signes et des degrés de continuité culturelle. C'est cependant à partir de corpus distincts de part et d'autre de l'Atlantique que furent rassemblées des données qui se prêtent de façon inégale à la comparaison. Ce n'est pas le moindre intérêt de cet ouvrage que d'aborder les rituels par plusieurs facettes et approches et d'ouvrir plusieurs brèches dans la définition de la culture comme un tout homogène que l'immigré emporterait dans ses déplacements et maintiendrait dans son intégralité.

Avant de rappeler quelques résultats de ces comparaisons axées sur le rite, il me semble important d'attirer l'attention d'abord sur deux articles à première vue hors sujet, qui traitent pour leur part du conte et de sa diffusion entre la métropole et son ex-colonie. Ces articles posent sur un autre terrain, mais de façon pertinente, la question préalable de la construction en partie arbitraire des sources au départ de toute comparaison. Dans un long texte qui fait l'historique de la fonction idéologique de certains colloques et musées créés en France à l'aube de la Seconde Guerre mondiale, Catherine Velay-Valentin fait le procès du folklore. Tant en Allemagne qu'en France, l'objet folklorique fut sélectionné et intégré dans une conception figée d'une culture populaire gommant tout rapport de domination, ce qui constitue une faille majeure d'une discipline qui a ainsi contribué à la mise en scène des homogénéités nationales. L'auteure trouve des traces de cette approche dans les études folkloriques québécoises de l'après-guerre, du moins dans la correspondance de Luc Lacourcière avec des folkloristes français intéressés à retrouver outre-mer des vestiges de cette culture française d'origine jugée menacée.

Tout au contraire, rétorque Vivian Labrie, Luc Lacourcière appartenait à une école de pensée américaine; c'est de ce côté qu'il orientait les étudiants et qu'il 
comptait ses principaux réseaux scientifiques. À partir du répertoire d'un conteur, l'auteure reconstitue le mélange de transmission, d'invention et de rapport au présent qui se manifeste dans sa trajectoire. En se portant à la défense du conte oral, Labrie a choisi un conteur acadien, héritier d'un conteur irlandais comme des mille et une nuits, ce qui lui semble aller à l'encontre de l'hypothèse de la recherche d'une culture homogène à travers l'oralité puisque les contes québécois conduisaient bien souvent vers un mélange culturel de type américain. On trouvera divers indices de ces transformations tant dans les règles de la prénomination (Josée Gauthier) que dans la langue (Thomas Lavoie), mais ce sont surtout les rituels qui ont fait l'objet de comparaisons. Dans les autres articles, les différences observées entre les rituels français et québécois sont aussi ramenées aux enracinements territoriaux, aux appartenances sociales et religieuses et aux expériences différentes de chaque groupe étudié, tandis que l'étude des dynamiques familiales dirige notre attention vers les processus microsociologiques révélateurs des interactions sociales au centre des rituels.

La comparaison des remèdes et thérapies populaires examinés à partir de divers corpus français et québécois fait apparaître, selon Françoise Loux et Francine Saillant, des différences qu'elles renvoient aux adaptations en terre américaine, aux influences amérindiennes comme à une histoire religieuse plus rigoriste au Québec. Face à la rareté des remèdes religieux dans les archives québécoises, faut-il retenir l'autre hypothèse avancée de l'oubli possible de nos folkloristes, dans leurs cueillettes, de ces gestes guérisseurs perçus dans la catégorie de la prière plutôt que du folklore? Cela dit, la question des temporalités reliées aux phénomènes observés et celle des processus de diffusion, de transmission d'abandon et d'appropriation ou d'invention des pratiques rituelles demeurent fort complexes et ce livre contient ample matière à réflexion. Réunissant trois études sur le trousseau de mariage en France, Agnès Fine s'attache à en dégager la symbolique identitaire des arts de la couture pour les jeunes filles dans le contexte ancien. Là encore, une comparaison avec le Québec permettrait d'approfondir l'analyse puisque le marquage du linge ne semble pas avoir été transposé dans un pays qui a pourtant compté ses brodeuses.

Gérard Bouchard, Michelle Salitot et Martine Segalen notent la difficulté de traiter le rite de mariage dans le long terme. Abandonnant la question de l'origine, c'est donc à partir d'enquêtes minutieuses sur deux terrains d'observations menant aux années 1920-1950, soit des paroisses rurales poitevines et québécoises, qu'ils examinent des séquences détaillées de rituels de mariages religieux. Dans l'ensemble, le rituel français est à la fois plus complexe et stéréotypé, impliquant davantage la communauté, alors que le rituel québécois, moins élaboré et plus variable, demeure restreint à la famille et à la parenté. Ils reviennent en conclusion à l'hypothèse de l'émiettement des modèles rituels régionaux venus de France.

Gérard Bouchard, René Hardy et Josée Gauthier poursuivent leurs analyses à l'échelle régionale en comparant les rituels de mariage dans six régions québécoises. Sans y déceler de véritables différences qui feraient du mariage un marqueur 
identitaire régional, l'étude révèle par ailleurs des clivages ville-campagne révélateurs d'une modernisation en cours. Le modèle urbain est également manifeste dans les chansons de noce étudiées par Anne-Marie Desdouits, tandis que le rite des débuts chez les jeunes bourgeoises montréalaises étudié par Denise Girard semble avoir contribué, dans les années 1925-1935, à circonscrire un marché du mariage qui inclut les jeunes anglophones de même milieu. Un rite du mariage simplifié et contraignant semble aussi avoir servi de marqueur identitaire chez les Français chrétiens d'Algérie à l'époque coloniale (Michèle Baussant), tandis que la simplicité du rite et la transmission de la Bible par les parents des époux contribuaient à différencier les groupes protestants minoritaires du Poitou (Michelle Salitot).

En 1995, Martine Segalen dénote une véritable expansion des rituels en France à mesure que le mariage échappe à une norme religieuse. Elle suggère que le rituel exprime moins un rite de passage que l'expression du compromis entre le couple déjà créé et la constellation familiale. Comparant le cortège de mariage hier et aujourd'hui au Québec, Martine Tremblay observe à partir d'un petit nombre de cas des simulacres de séparation des conjoints vivant en cohabitation et une entrée à l'église qui expriment symboliquement la transformation des liens intergénérationnels. Laurence Hérault en examinant les mariages au sein de trois familles sur deux générations nous laisse entrevoir comment se construisent les homogénéités de pratiques rituelles dans une famille, davantage par l'expérience de mariages successifs au sein d'une génération que par la transmission intergénérationnelle. Encore peu explorés, les rites contemporains viennent donc éclairer les transformations des pratiques culturelles en cours depuis quelques siècles; celles-ci livrent en retour certaines significations sur les permanences, les inventions et les éclipses du rite dans certains secteurs des sociétés actuelles. 